\title{
An Examination of Transformational Leadership among Graduating Baccalaureate Nursing Students and Practicing Nurses
}

\author{
Lizy Mathew* \\ The William Paterson University of New Jersey, Wayne, USA \\ Email: $\underline{\text { mathewl@wpunj.edu }}$
}

Received 28 August 2014; revised 27 September 2014; accepted 13 October 2014

Copyright (C) 2014 by author and Scientific Research Publishing Inc.

This work is licensed under the Creative Commons Attribution International License (CC BY). http://creativecommons.org/licenses/by/4.0/

(c) (i) Open Access

\begin{abstract}
Leadership skills are essential among nurses to address the challenges faced by the nursing profession. This quantitative comparative study examined five components of transformational leadership skills as outlined by Kouzes and Posner among graduating baccalaureate nursing students and practicing nurses [1]. Five leadership components were used to examine if differences existed among the groups studied. The results indicated significant differences for modeling the way, inspiring a shared vision, enabling others to act, and encouraging the heart. The study revealed that nursing students graduating from generic and accelerated programs have inferior leadership skills compared to nurses in clinical practice. The results may be useful in leadership training of nursing students through collaborative practices between practice settings and nursing schools to improve patient safety.
\end{abstract}

\section{Keywords}

Nursing Students, Leadership

\section{Introduction}

According to Lindsey (2009), there is a potential shortage of nurse leaders in clinical settings [2]. Baccalaureate nursing programs may not be training nursing students adequately to become future nurse leaders. Because of lack of suitable clinical placement sites and the lack of efficient use of available sites, nursing students are not achieving the desired educational outcomes to become nurse leaders [3]. The purpose of this quantitative com-

*Associate Professor. 
parative study was to examine transformational leadership qualities of graduating nursing students and nurses in clinical practice.

\section{Background}

Lindsey addresses the potential for lack of future clinical nurse leaders [2]. Cangelosi and Whitt questioned the efficacy of many of the nursing programs in preparing nurse leaders [4]. Scholars such as Kline and Hodges raised concern over nursing schools competing for clinical placements and asked whether the lack of suitable clinical placement sites jeopardize the integrity of nursing curricula [3]. The general problem is a lack of efficacy of nursing programs in preparing nursing students to become effective leaders in clinical settings [4]. Leadership skills are essential in making sound clinical judgments in the nursing profession. The specific problem is the lack of evidence in research literature indicating novice nurses possess adequate leadership skills needed to meet the demands of nursing profession and healthcare industry.

As a result, the nursing profession is forced to welcome more and more novice nurses to assume leadership positions and act as role models to students and new nurses. Upon graduation from nursing schools, new nurses may remain in the novice stage for months or years prior to becoming competent and proficient nurses with leadership qualities [5]. Therefore, leadership training in nursing education is essential. Novice nurses are accountable for other personnel such as nursing assistants and collaborate with the healthcare team.

\section{Theoretical Framework}

Nursing practice has its foundations in nursing theories, many of which focused on leadership and management. "Leadership can be defined as a multifaceted process of identifying a goal or target, motivating other people to act, and providing support and motivation to achieve mutually negotiated goals" [6]. "The five practices of exemplary leadership" defined by Kouzes and Posner, "model the way, inspire a shared vision, challenge the process, enable others to act and encourage the heart" support this definition [1]. The LPI-Self (The Leadership Practices Inventory), a thirty-item survey instrument by Kouzes and Posner was used in this study [1]. The study also looked at variables that may have an effect on leadership qualities of nurses. Education, age, gender, position held and years of nursing experience were selected as variables in practicing nurses. GPA, age, and gender were selected as variables in the student groups.

The following research questions guided this study:

RQ1: Is there a difference between graduating nursing students and nurses in clinical practice with respect to leadership skills?

RQ2: Are the individuals' characteristic profiles, including variables such as age, gender, Grade Point Average (GPA), education, years of nursing experience, position held, correlated with leadership skills, overall or within either of the study groups?

RQ3: After adjusting for possible effects of intervening variables such as age, gender, GPA, and education, of nursing students, and age, gender, years of nursing experience, and position held of nurses in clinical practice, is there a significant difference in leadership skills between baccalaureate nursing students and nurses in clinical practice?

The following hypotheses were tested:

$\mathrm{H} 1_{0}$ : There is no difference in the leadership skills among the four groups; three groups of graduating nursing students and one group of practicing nurses.

$\mathrm{H} 2_{0}$ : Practicing nurses will not demonstrate higher leadership skills compared to graduating nursing students.

$\mathrm{H}_{0}$ : Leadership skills are not positively affected by intervening variables such as age, GPA, years of nursing experience, position held and education among students and nurses in clinical practice.

\section{Method}

The research design for this quantitative study was a prospective, comparative design. This study used a nonexperimental method using descriptive and inferential statistical analysis. The groups studied were (a) graduating nursing students from generic baccalaureate nursing programs, (b) graduating nursing students with RNBSN degree, (c) graduating nursing students from accelerated baccalaureate degree, and (d) practicing nurses. RN-BSN students are practicing nurses who hold an associate or diploma in nursing and obtaining a baccalaureate degree in nursing. Nursing students enrolled in accelerated nursing programs generally possess a bacca- 
laureate degree in science and complete the nursing degree in 12 to 16 months.

The study used two sets of instruments: The Leadership Practice Inventory-Self (LPI) to measure leadership skills and a demographic questionnaire. The LPI, a 30-item questionnaire, measure behaviors on a scale of 1 to 10 , with 1 being never and 10 being almost always are grouped under the five practices of exemplary leadership, each including six practices [4]. The five practices of exemplary leadership are "model the way, inspire a shared vision, challenge the process, enable others to act, and encourage the heart" [4]. The Leadership Practices Inventory-Self had a Cronbach's alpha of 0.93 for this study, indicating the survey was reliable. Reliability coefficients (alpha) of the Leadership Practice Inventory-Self are between 0.82 and 0.92, and the test-retest reliability is reported as 0.93. Kouzes and Posner reported internal validity of LPI measured by Cronbach's Alpha as strong, with all scales above the 0.75 level [4].

The study also used a demographic questionnaire to study the effect of intervening variables such as age, gender, current Grade Point Average, and the type of baccalaureate program graduating nursing students attended. Demographic data from practicing nurses included age, gender, the highest degree held, the number of years of nursing experience of the participants, and whether the participants hold a leadership position in practice. The participants were selected conveniently from four nursing schools and two hospitals located in northeastern New Jersey in the United States. Data on 310 individuals (155 students and practicing nurses each) were determined appropriate for this study. This was based on formal sample size and power calculations.

\section{Data Collection and Analysis}

The institutional review boards of all the institutions were petitioned and permissions were obtained to conduct the study. The investigator visited the institutions and obtained informed consent from the participants. Analysis of data was conducted using SPSS version 14.0 statistical software. Results were considered statistically significant if the $p$-value is less than or equal to a pre-specified alpha-level of 0.05 . Initial analyses included descriptive statistics of demographic data to describe the characteristics of the sample.

\section{Results}

\subsection{Practicing Nurses}

Majority of the practicing nurses reported their gender as female (134/145). Nurses in clinical practice had a mean age of 44.63 with age ranging from 22 to 67 . The majority (70.4\%) of practicing nurses reported having earned a Bachelor of Science in Nursing. Approximately 50\% (73) of the 145 practicing nurses reported holding a leadership position in nursing. Of the 145 nurses who participated in the study, 123 (84.4\%) reported having more than five years of experience and about $14 \%$ reported having less than five years of experience.

\subsection{Students}

One hundred thirty seven generic (64.9\%), 45 RN-BSN (21.3\%), and 29 accelerated (13.7\%) graduating students participated in the study. Students in the RN-BSN program reported the highest mean Grade Point Average $(M=3.61)$ and students in the Generic program reported the lowest mean Grade Point Average $(M=3.34)$. Students in the RN-BSN program had the highest mean age (38.91) and a minimum of 21 and a maximum of 44 years old. Students in the generic program had the lowest mean age (25.23) with a minimum of 21 and a maximum of 45 . Students in the accelerated program had a mean age of 30.93 with a minimum of 22 and a maximum of 44 . All three groups were predominantly female.

\section{Hypothesis Testing}

\subsection{Research Question 1}

RQ 1: Is there a difference between graduating nursing students and nurses in clinical practice with respect to leadership skills?

Results of the one-way analysis of variance (see Table 1) indicate there are significant differences between groups only for inspiring a shared vision, $F(2,208)=3.90 ; p=0.02$. The results of the Games-Howell indicate significant differences between RN-BSN and both generic and accelerated students (Table 2). Generic students had a mean of 43.07, accelerated students had a mean of 41.79, and RN-BSN students had a mean of 46.80 (Table 3). 
Table 1. Analysis of variance: Leadership skills by group.

\begin{tabular}{ccccc}
\hline & & $d f$ & $F$ & $p$ \\
\hline Inspire & Between Groups & 2 & 3.90 & 0.02 \\
& Within Groups & 208 & & \\
Total & 210 & & \\
\hline
\end{tabular}

Table 2. Games-howell post hoc analysis.

\begin{tabular}{cccccccc}
\hline & & & \multicolumn{4}{c}{ 95\% Confidence Interval } \\
\hline \multirow{2}{*}{ (I) group } & (J) group & Mean Difference (I-J) & SE & $p$ & Lower Bound & Upper Bound \\
& Accelerated & 1.28 & 1.53 & 0.68 & -2.41 & 4.97 \\
& RN-BSN & $-3.73^{*}$ & 1.32 & 0.02 & -6.88 & -0.58 \\
\multirow{2}{*}{ Accelerated } & Generic & -1.28 & 1.53 & 0.68 & -5.00 & 2.41 \\
& & & & & & -1.00 \\
& \multirow{2}{*}{ RN-BSN } & Generic Accelerated & $-5.01^{*}$ & 1.67 & 0.01 & -9.0 & -1.00 \\
& & $3.73^{*}$ & 1,32 & 0.016 & 0.58 & 6.88 \\
\hline
\end{tabular}

*The mean difference is significant at the 0.05 level.

Table 3. Group means: Inspiring a shared vision.

\begin{tabular}{cccc}
\hline Group & $M$ & $N$ & $S D$ \\
\hline Practicing Nurses & 44.93 & 145 & 9.12 \\
Generic & 43.07 & 137 & 9.49 \\
Accelerated & 41.79 & 29 & 6.98 \\
RN-BSN & 46.80 & 45 & 7.03 \\
Total & 44.20 & 356 & 8.96 \\
\hline
\end{tabular}

\subsection{Research Question 2}

RQ2: Are the individuals' characteristic profiles, including variables such as age, gender, Grade Point Average (GPA), education, years of nursing experience, position held, correlated with leadership skills, overall or within either of the study groups?

Regression analysis was completed overall and within each group to assess the differences and relationships between the characteristic profiles and the five leadership component scores. To correct for possible Type 1 error, rejecting the null hypothesis when it is false, the alpha level was adjusted from 0.05 to 0.01 because 5 tests were conducted for each comparison (for each of the 5 dependent variables). Using a Bonferonni correction of alpha/number of tests, $0.05 / 5=0.01$.

All participants: Regression analysis with all participants included, and group, age, and gender as the independent variables, the results indicate modeling the way $\left(R=0.19\right.$, adj. $\left.R^{2}=0.03, p=0.007\right)$, was statistically significant. The results further indicated only age was a significant predictor of score on modeling the way with older nurses and older students scoring high. However, only a minimal amount of the variance is explained with age as the only predictor (Table 4).

The results indicated that inspiring a shared vision $\left(R=0.18\right.$, adj. $\left.R^{2}=0.02, p=0.01\right)$, was statistically significant. The results further indicated that only age was a significant predictor of score on inspiring a shared vision. However, only a minimal variance is explained with age as the only predictor (Table 5).

The results indicated that challenging the process $\left(R=0.17\right.$, adj. $\left.R^{2}=0.02, p=0.02\right)$, was statistically significant. The results also indicated that only age was a significant predictor of score on challenging the process. However, only a minimal variance is explained with age as the only predictor (Table 6). 
Table 4. Regression coefficients: Modeling the way.

\begin{tabular}{cccccc}
\hline & $B$ & $S E$ & Beta & $t$ & $p$ \\
\hline (Constant) & 46.34 & 1.44 & & 32.28 & $<0.001$ \\
Group & -0.31 & 0.36 & -0.05 & -0.86 & 0.39 \\
Age & 0.09 & 0.03 & 0.17 & 3.05 & 0.002 \\
Gender & 0.29 & 1.19 & 0.01 & 0.24 & 0.81 \\
\hline
\end{tabular}

Table 5. Regression coefficients: Inspiring a shared vision.

\begin{tabular}{cccccc}
\hline & $B$ & $S E$ & Beta & $t$ & $p$ \\
\hline (Constant) & 39.78 & 1.99 & & 20.02 & $<0.001$ \\
Group & 0.42 & 0.50 & 0.05 & 0.85 & 0.40 \\
Age & 0.11 & 0.04 & 0.15 & 2.76 & 0.006 \\
Gender & -2.69 & 1.64 & -0.088 & -1.64 & 0.10 \\
\hline
\end{tabular}

Table 6. Regression coefficients: Challenging the process.

\begin{tabular}{cccccc}
\hline & $B$ & $S E$ & Beta & $t$ & $p$ \\
(Constant) & 38.61 & 1.90 & & 20.32 & $<0.001$ \\
Group & 0.55 & 0.48 & 0.06 & 1.14 & 0.25 \\
Age & 0.12 & 0.04 & 0.17 & 3.08 & 0.002 \\
Gender & -0.97 & 1.57 & -0.03 & -0.62 & 0.54 \\
\hline
\end{tabular}

There was no significant relationship between group, age, and gender and enabling others to act $(R=0.16$; $p$ $=0.07)$. There was also no significant relationship between group, age, and gender and encouraging the heart ( $R$ $=0.09 ; p=0.40$ ). In practicing nurses, regression analysis was conducted to determine if years of experience, level of education, and leadership position were significantly related to leadership skills. The results indicate there is no significant relationship for modeling the way $(R=0.14 ; p=0.43)$, inspiring a shared vision $(R=0.20$; $p=0.12)$, challenging the process $(R=0.15 ; p=0.39)$, enabling others to act $(R=0.11 ; p=0.64)$, or encouraging the heart $(R=0.17 ; p=0.27)$. There was no linear relationship between GPA and any leadership variables for nursing students (Table 7).

\subsection{Research Question 3}

RQ3: After adjusting for possible effects of intervening variables such as age, gender, GPA, and education, of nursing students, and age, gender, years of nursing experience, and position held of nurses in clinical practice, is there a significant difference in leadership skills between nursing students and nurses in clinical practice?

The only demographic variable that was significant in previous analyses was age; therefore, only age was included as an intervening variable in the multivariate analysis of covariance. Practicing nurses and $R N$-BSN students scored higher in leadership components compared to Generic and Accelerated students in respect to the five leadership practices. Results of the MANCOVA indicate no significant differences for age $F(5,336)=1.73$; $p=0.13$. Results of the MANCOVA indicate no significant differences for group $F(15,1014)=1.73 ; p=0.35$ (Table 8).

\section{Conclusions and Implications for Nursing}

The findings indicated that graduating baccalaureate nursing students from generic and accelerated nursing programs showed significantly lower scores in four of the five transformational leadership components compared to 
Table 7. Nursing students: Correlation between GPA and leadership variables.

\begin{tabular}{ccc}
\hline Variable & $r$ & $p$ \\
MOD-AV & 0.029 & 0.677 \\
INSP-AV & -0.012 & 0.865 \\
CHAL-AV & 0.043 & 0.538 \\
ENAB-AV & 0.019 & 0.791 \\
ENCR-AV & -0.026 & 0.716 \\
\hline
\end{tabular}

${ }^{* * *}$ Correlation is significant at the 0.01 level (2-tailed).

Table 8. Multivariate analysis of covariance.

\begin{tabular}{ccccc} 
Effect & $F$ & Hypothesis $d f$ & Error $d f$ & $p$ \\
\hline Intercept & 320.37 & 5 & 336 & $<0.001$ \\
Age & 1.73 & 5 & 336 & 0.128 \\
Group & 1.10 & 15 & 1014 & 0.350
\end{tabular}

practicing nurses and RN-BSN students, who are also practicing nurses. Education, age, position held and years of experience of practicing nurses did not play a role in the leadership skills of nurses in clinical practice. Increasing quality clinical experience in nursing education may increase leadership skills among nursing students and prepare new graduates to become better leaders in nursing.

The results of this study showed that nurses in leadership positions did not perceive themselves as better transformational leaders compared to staff nurses. Age, gender, education, years of nursing experience, and position held were not predictive factors for higher transformational skills among nurses in clinical practice. Nurses with higher education levels and nurses with more than 5 years of experience did not demonstrate higher leadership skills. More studies are needed in this area to find other variables that facilitate transformational leadership skills.

There is increased call now for engaging students in clinical practice projects as part of leadership training to improve quality and safety in healthcare [7]. The results of the study may be used by nursing schools to engage students in clinical practice safety projects as part of leadership training among nursing students. Nurse leaders in nursing education and clinical practice may use these findings to foster collaborative practice among clinical settings and nursing schools to foster leadership among nurses and safety in healthcare.

\section{References}

[1] Kouzes, J.M. and Posner, B.Z. (2002) The Leadership Challenge. 3rd Edition, Jossey-Bass, San Francisco.

[2] Lindsey, P. (2009) Starting an Accelerated Baccalaureate Nursing Program: Challenges and Opportunities for Creative Educational Innovations. Journal of Nursing Education, 48, 279-281.

[3] Kline, K.S. and Hodges, J. (2006) A Rational Approach to Solving the Problem of Competition for Undergraduate Clinical Sites. Nursing Education Perspectives, 27, 80-83.

[4] Cangelosi, P.R. and Whitt, K.J. (2005) Accelerated Nursing Programs. Nursing Education Perspectives, 26, $113-116$.

[5] Uhrenfeldt, L. and Hall, E.O.C. (2007) Clinical Wisdom among Proficient Nurses. Nursing Ethics, 14, 387-398. http://dx.doi.org/10.1177/0969733007075886

[6] Davidson, P.M., Elliott, D. and Daly, J. (2006) Clinical Leadership in Contemporary Nursing Practice: Implications for Nursing in Australia. Journal of Nursing Management, 14, 180-187. http://dx.doi.org/10.1111/j.1365-2934.2006.00555.x

[7] McPhee, M., Espezel, H., Clauson, M. and Gustavson, K. (2009) A Collaborative Model to Introduce Quality and Safety Content into the Undergraduate Nursing Leadership Curriculum. Journal of Nursing Care Quality, 24, 83-89. http://dx.doi.org/10.1097/NCQ.0b013e31818f5537 
Scientific Research Publishing (SCIRP) is one of the largest Open Access journal publishers. It is currently publishing more than 200 open access, online, peer-reviewed journals covering a wide range of academic disciplines. SCIRP serves the worldwide academic communities and contributes to the progress and application of science with its publication.

Other selected journals from SCIRP are listed as below. Submit your manuscript to us via either submit@scirp.org or Online Submission Portal.
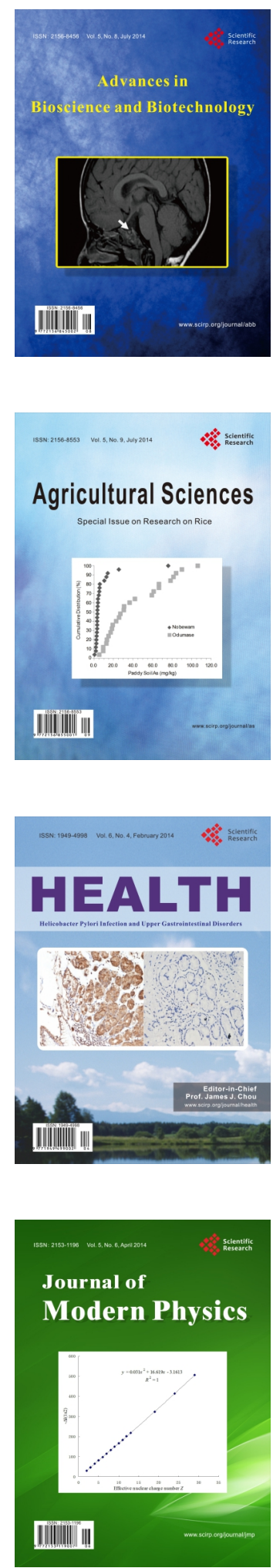
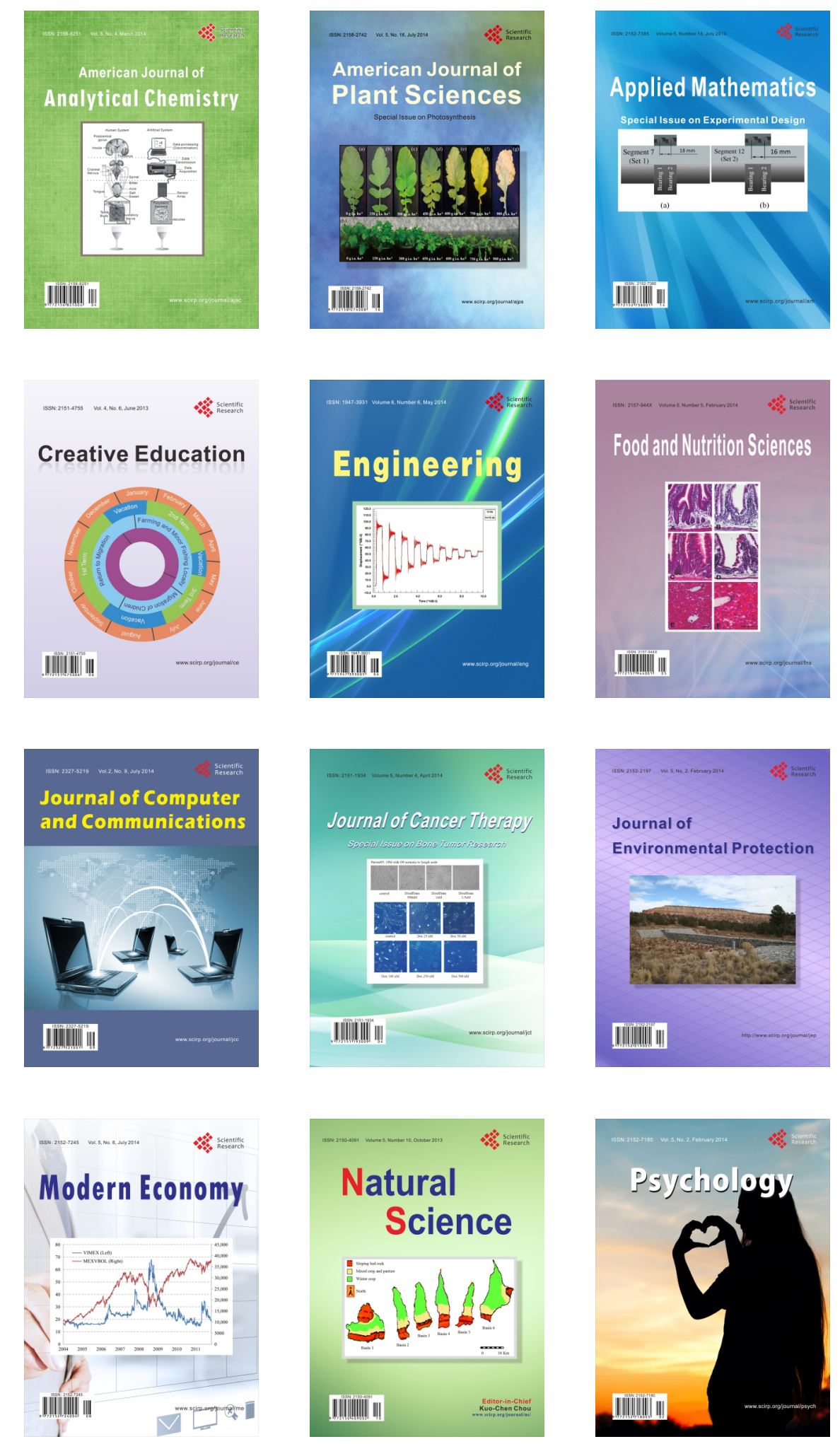